\title{
A Tale of Two Degrees: Always AsK Why
}

\author{
John Tamine
}

Sponsored Affiliate Researcher, University of Pittsburgh, Pittsburgh, PA 15260

\begin{abstract}
Variations of the familiar formulae for inter-converting temperature readings on the Celsius and Fahrenheit scales are developed, and the genesis of the alternative formulae are attributed to the process of reflective study. The opportunity to gain a better intuitive grasp of just exactly what one is doing and even the possibility of finding better ways of doing things are emphasized as rewards of reflection, along with the ensuing sense of personal accomplishment that fuels self-motivation and engenders self-esteem.
\end{abstract}

\section{KEYWORDS}

Educating The Educators, Learning Theories, Mnemonics/Rote Learning, Self-Motivation, Self-Esteem.

\section{INTRODUCTION}

It was the coolest of times, it was the uncoolest of times... No wait, that's from a different tale. Here we go... A website selling posters has one entitled "Tradition," (see Figure 1) which has a photo taken at the annual running of the bulls in Pamplona Spain with the caption, "Just because you've always done it that way doesn't mean it's not incredibly stupid." [1]

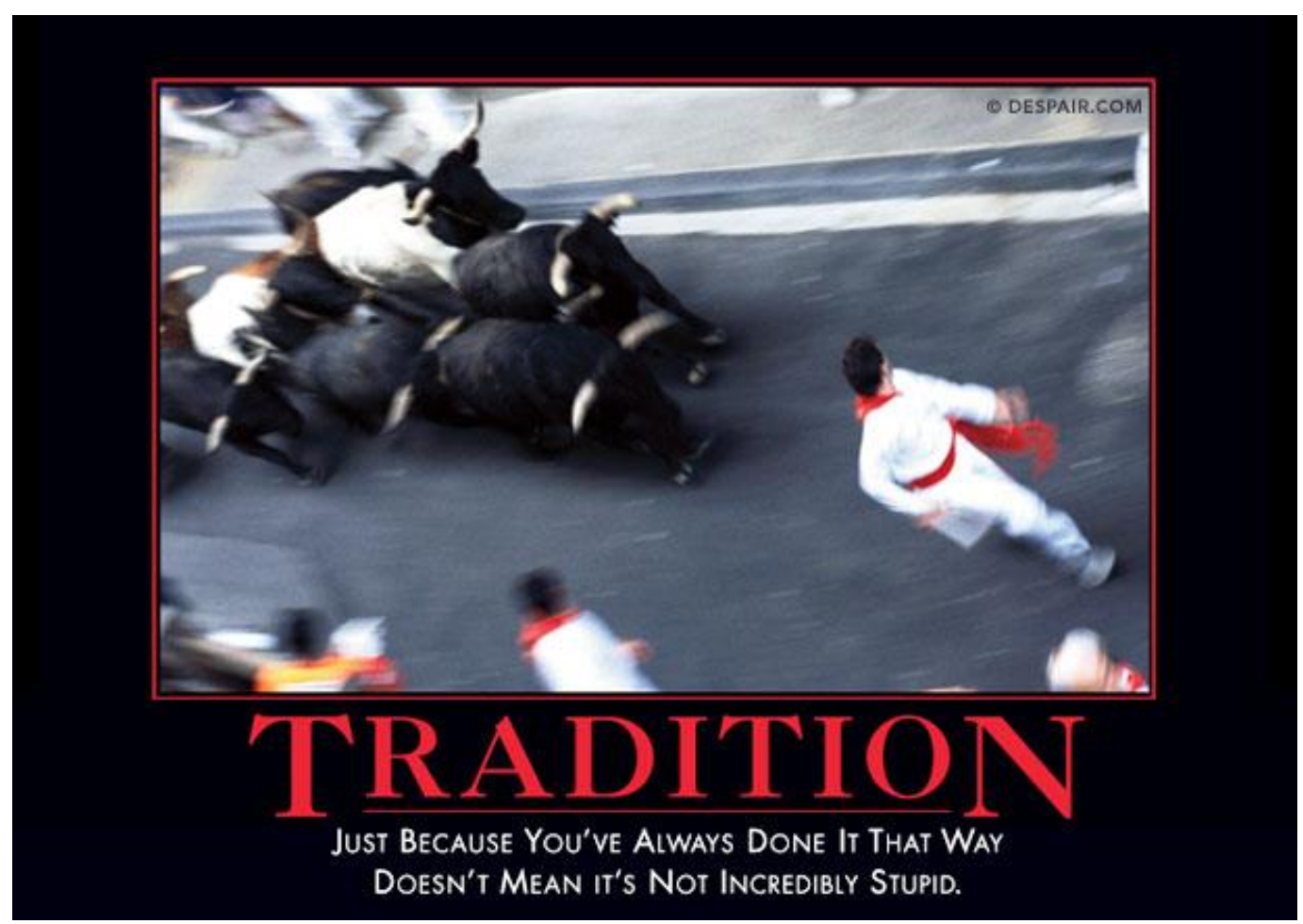

Figure 1. Tradition 
There's a kernel of wisdom within the sarcasm. We all have a natural tendency to learn things by rote and not question what has been done before, especially when it's taught to us by a respected authority figure, and most of all, when it works. Even the most self-motivated and inquisitive of students often stumble into this pitfall. In particular, when it comes to a method for calculating some desired result, we rarely reflect on the details of the procedure or ask ourselves, "Exactly why is it done this way?" In one respect that makes sense. The old adage, "Don't waste time reinventing the wheel," seems to be sound advice. Far less would be accomplished and progress would slow to a snail's pace if everyone began everything from scratch and questioned every step in the process. The benefit appears obvious. But the unintended consequence and less obvious price we pay when we neglect to ask ourselves if it could be done differently, if it could be done more efficiently, are that opportunities for progress or even simply greater insight might be lost.

\section{DISCUSSION}

Not long ago, I was called upon to teach a survey course to non-science majors, and in due course, I had to pause for a moment to refresherize my rememberification of how to convert Celsius to Fahrenheit, and vice versa. I suspect most readers were taught the same equations as I. In all of the textbooks I have encountered over the years (for an abridged list, see [2-12]), they're the only equations I recalled having seen. I suspect most readers memorized them by rote, just as I did. To convert a temperature reading in Celsius $\left(T_{\mathrm{C}}\right)$ to the corresponding temperature reading in Fahrenheit $\left(T_{\mathrm{F}}\right)$, first multiply the reading in Celsius by nine-fifths, then add $32^{\circ}$ to the product,

$$
\frac{9}{5} T_{\mathrm{C}}+32^{\circ}=T_{\mathrm{F}}
$$

To convert a temperature reading in Fahrenheit to the corresponding temperature reading in Celsius, first subtract $32^{\circ}$ from the reading in Fahrenheit, then multiply the difference by fiveninths,

$$
\left(T_{\mathrm{F}}-32^{\circ}\right)\left(\frac{5}{9}\right)=T_{\mathrm{C}}
$$

But if it's been a while since the last time I needed to do this, I have to pause to figure out when do I and add or subtract, and when do I use (5/9) or (9/5). That means look up the formulae, or figure them out from the operational definitions of the Fahrenheit and Celsius temperature scales. Figuring it out takes only a few seconds, but step-by-step, painfully goes more or less as follows.

Making a temperature scale requires two reference points, two different temperatures that are experimentally reproducible and physically constant (under specific conditions). Then a number (degree) is arbitrarily assigned to each physically constant temperature and this defines the scale, that is, how many degrees separate those two physically constant temperatures, or putting it another way, the size of one degree. Both the Celsius and Fahrenheit scales use the same two physical constants, the freezing point and boiling point of pure water at 1 atm pressure. [13] The freezing point $(\mathbf{f p})$ of water is designated $0^{\circ} \mathrm{C}$, and $32^{\circ} \mathrm{F}$, while the boiling point (bp) of water is designated $100^{\circ} \mathrm{C}$, and $212^{\circ} \mathrm{F}$. Since Fahrenheit chose $32^{\circ}$ and $212^{\circ}$ but Celsius chose $0^{\circ}$ and $100^{\circ}$, that means there are 180 Fahrenheit degrees but only 100 Celsius degrees separating the two points, This implies that Fahrenheit degrees are smaller (more of them) and Celsius degrees are larger (fewer of them). To be precise, one Celsius degree is 180/100 or 9/5 times larger than a Fahrenheit degree. Conversely, one Fahrenheit degree is only 100/180, or 5/9 as large as a 
Celsius degree. Thus, the need for the fractional factors in Equations (1) and (2) can be understood.

But converting a temperature reading on one scale to a temperature reading on the other involves more than just a conversion factor for the size of the degrees on each scale. There's also the need to know the difference between the temperature reading to be converted, and the numerical value assigned to one of the fixed physical temperatures used to define the scale. Since the $\mathbf{f p}$ and $\mathbf{b p}$ of water are the fixed temperatures upon which both scales are based, perhaps it seemed natural or necessary to use one of those for the conversion of temperature readings. The freezing point was chosen (and for the moment I leave it to the reader to reflect on why). So the logical steps involved in the conversion of a temperature reading on one scale entail multiplying by the factor that accounts for the different sizes of the degrees on each scale, and a comparison of how far the reading is from some fixed point on each scale. The end results of combining these two steps are the formulae expressed in Equations (1) and (2) that we have all come to know, if not love.

On that day, however, after 50 yeas of not remembering them, it occurred to me, maybe if I rearrange the equations I could make them easier for me to remember. Once I put my attention upon the equations, I thought about the process, conceptually, rather than seeing the equations merely as instructions for a sequence of arithmetic operations. When I did that, I realized that the fp of water isn't the one and only fixed reference point that could be used to derive conversion equations. Why not use the bp of water as the fixed reference temperature instead? Good question! Doing so, Equation (1) would be replaced by

$$
\left(T_{\mathrm{C}}-100^{\circ}\right)\left(\frac{9}{5}\right)+212^{\circ}=T_{\mathrm{F}}
$$

and Equation (2) would be replaced by

$$
\left(T_{\mathrm{F}}-212^{\circ}\right)\left(\frac{5}{9}\right)+100^{\circ}=T_{\mathrm{C}}
$$

These formulae work exactly as well as the familiar ones. Readers are encouraged to entertain themselves verifying this by performing as many conversions as they like.

However, upon a little more reflection examination of Equations (3) and (4) reveals that there's no mathematical reason limiting the choice of reference temperature to the $\mathbf{f p}$ or $\mathbf{b p}$ of water. Any point on the two scales that correspond to the same physical temperature will suffice, for example "room temperature" $\left(20^{\circ} \mathrm{C}=68^{\circ} \mathrm{F}\right)$, which would give

$$
\left(T_{\mathrm{C}}-20^{\circ}\right)\left(\frac{9}{5}\right)+68^{\circ}=T_{\mathrm{F}}
$$

and

$$
\left(T_{\mathrm{F}}-68^{\circ}\right)\left(\frac{5}{9}\right)+20^{\circ}=T_{\mathrm{C}}
$$

respectively. Of course, someone else might have a different idea of where the thermostat should be set, and after a heated debate, derive analogous but numerically different formulae.

Or Absolute Zero could be used as the fixed reference point (that has a certain authoritativesounding appeal), and the formulae become 


$$
\left(T_{\mathrm{C}}+273.15^{\circ}\right)\left(\frac{9}{5}\right)-459.67^{\circ}=T_{\mathrm{F}}
$$

and

$$
\left(T_{\mathrm{F}}+459.67^{\circ}\right)\left(\frac{5}{9}\right)-273.15^{\circ}=T_{\mathrm{C}}
$$

respectively.

Now that you are reflecting upon the matter with me, it should be clear that regardless of the fixed reference temperature chosen, it's possible to derive formulae for the inter-conversion of temperature readings on the two scales. But so far, the calculations are not simpler, nor the formulae easier to remember. In fact, Equations (3)-(8) require more steps than Equations (1) and (2) and memorization of two numerical values rather than one. The reason for choosing the freezing point of water ought to be crystallizing in your mind now. Recognize that in Equations (3)-(8) the procedure is the same. First subtract the reference temperature on that scale, multiply, then add the reference temperature on the other scale. Equations (1) and (2) are shorter because choosing the freezing point of water means that the reference point has a numerical value of zero (the additive identity) on one of the scales, and thus one of those operations and one of those numbers effectively "disappear" from the Equations

Further reflection might lead us to ask, "Is it possible that there is some other choice for the fixed reference temperature that would yield formulae that are less complicated than Equations (1) and (2) rather than more so?" The first thought might be to use $0^{\circ} \mathrm{F}$, since getting a zero into the mix made Equations (1) and (2) simpler. But no, this only gives

$$
\left(T_{\mathrm{C}}+17 \frac{7}{9}^{\circ}\right)\left(\frac{5}{9}\right)=T_{\mathrm{F}}
$$

and

$$
\frac{9}{5} T_{\mathrm{F}}-17 \frac{7}{9}^{\circ}=T_{\mathrm{C}}
$$

Respectively, which are clearly no improvement in terms of operational simplicity or ease of memorization. Like Equations (1) and (2), Equations (9) and (10) only require us to remember one numerical value of the reference temperature instead of two, but the equations are neither simpler nor more intuitive.

Perhaps a better question to ask is, "If the key to making the equations simpler and easier to remember doesn't lie in making one of the operations disappear (by choosing a numerical value of zero for one of the reference temperatures), where does it lie?" Observe that both pairs of Equations $(1 \& 2)$ and $(9 \& 10)$ use the same number in both equations, but in one the number must be added and in the other the number must be subtracted, while for each pair of Equations $(3 \& 4),(5 \& 6)$, and $(7 \& 8)$ the operations are always the same, subtract, then multiply, then add, but each equation has two different constants that alternate positions. Maybe the right question is, "Can the equations be made easier to remember by making them more symmetrical, that is, by having the same numerical constant in both equations and on both sides?" And, light bulb moment (did you beat me to it?), the way to do that is by choosing the one and only physical temperature that has the same numerical value on both the Celsius and the Fahrenheit scales, namely minus forty degrees $\left(-40^{\circ}\right)$. [14] The fact that it doesn't correspond to any familiar physical phenomenon [15] is irrelevant. It's chosen it for computational symmetry and 
mnemonic simplicity. Subtract negative $40^{\circ}$, multiply, then add negative $40^{\circ}$, or written in equation form

$$
\left(T_{\mathrm{C}}+40^{\circ}\right)\left(\frac{9}{5}\right)-40^{\circ}=T_{\mathrm{F}}
$$

and

$$
\left(T_{\mathrm{F}}+40^{\circ}\right)\left(\frac{5}{9}\right)-40^{\circ}=T_{\mathrm{C}}
$$

I must confess that as trivial as this may seem, at the moment this insight occurred to me, I was elated. Even though it's no great revelation, nor admittedly is getting Equations (1) and (2) straight a big deal, and the realization itself occurred in only a fraction of the time needed to compose this parable, still, it felt good. That feeling of elation lasted as long as it took to Google "temperature conversion formula" and discover that even though I had just derived Equations (11) and (12) all by my lonesome, I was not the first person to come up with the idea. [16] While that let most of the hot air out of my balloon, I was still left with a warm fuzzy feeling (and a mild elbow sprain from prematurely patting myself on the back).

\section{Conclusions}

I seem to vaguely recall that at some tender age, when I was first taught Equations (1) and (2), I disliked the dissymmetry of them. I found them inconvenient to remember, because I always needed to pause and mentally review their derivation in order to get them straight. I failed, however, to go that next step and ask myself if there might not be other ways to perform the conversions, ways that might be simpler or easier for me to remember. In my defense, I was so much older then, I'm younger than that, now. [17]

Now, I encourage my students, at all levels, in all courses, to do what I failed to do in this case, to take a moment to reflect on what we learn, and what we know. Stop and ask why we do things the way that we do, rather than assuming that the way we are taught is the only way, or even the best way. It is, in the popular jargon du jour, a teachable moment, and perhaps one of the truly important ones.

Sometimes we, as teachers, just want to get on with the class. Nevertheless, our students need to be encouraged to ask themselves, and us, "Why are things done this way?" "What's the reason?" "What's the rationale?" They should be reminded, In science, never be afraid to question authority. No matter how trivial or insignificant the question (or how much they may try our patience), as educators we must advocate that students take the time to reflect on the why. [18] The real concern is that students who learned only by rote will become teachers who teach only by rote, and test only by true-false and multiple-guess exams. At its most fundamental core, teaching is not about merely imparting facts, but rather, showing students how to think critically and solve problems creatively. It's about the process as much as the details. Rote learning is a bane and a scourge to the process of problem solving, to the higher goal of training a critical thinker. Reflection, asking why is the key to the process.

At the very least, by reflecting on the material, students and teachers can gain a firmer grasp of the concept or procedure at hand. And no one can predict when a flash of insight might turn out to be the next paradigm-shifting idea. Just because it's always been done a certain way doesn't 
mean there isn't a better way. But even when the insight is only a personal revelation, the satisfaction of conjuring up an original thought is addictive, no matter whether young or old, novice or master. It's the most powerful motivating force there is to stimulate the desire to study more diligently. And the more diligently we apply ourselves, the more frequent and more significant our insights and original thoughts will be. It's a positive feedback loop; a chainreaction; and it can all begin with a little reflection. Because in science, just as in the world, discovering the unknown cannot come from already knowing the answers, but only from asking the right questions.

\section{ACKNOWLEDGEMENTS}

I wish to express my profound gratitude to Professor Peter Wipf for being my sponsor at the University of Pittsburgh and thereby providing me with access to the University Library System.

\section{REFERENCES}

[1] http://www.despair.com/tradition.html

[2] McMurry, J. E.; Fay, R. C. Chemistry; th $^{\text {th }}$ Ed.; Prentice-Hall: Boston, 2011; p 13-14.

[3] Brown, T. L.; LeMay, Jr. H. E.; Bursten, B. E.; Murphy, C. J.; Woodward, P. M. Chemistry: The Central Science; $12^{\text {th }}$ Ed.; Prentice-Hall: Boston, 2011; p 17.

[4] Ebbing, D. D.; Gammon, S. D. General Chemistry; th $^{\text {th }}$ Ed.; Brooks/Cole: Belmont, 2011; p 21.

[5] Gilbert, T. R.; Kirss, R. V.; Foster, N.; Davies, G. Chemistry; $2^{\text {nd }}$ Ed.; W. W. Norton: New York, 2009; p 30-32.

[6] Blei, I.; Odian, G. General, Organic, and Biochemistry; $2^{\text {nd }}$ Ed.; W. H. Freeman: New York, 2009; p 25-26.

[7] Denniston, K. J.; Topping, J. J. Foundations of General, Organic, and Biochemistry; McGraw-Hill: Boston, 2008; p 27.

[8] Atkins, P.; Jones, L. Chemical Principles; $4^{\text {th }}$ Ed.; W. H. Freeman: New York, 2008; p A5.

[9] Yoder, C. H.; Suydam, F. H.; Snavely, F. A. Chemistry; $2^{\text {nd }}$ Ed.; Harcourt Brace Jovanovich: New York, 1980; p 12.

[10] Halliday, D.; Resnick, R. Fundamentals of Physics; John Wiley \& Sons: New York, 1970; p 348-349.

[11] Sienko, M. J.; Plane, R. A. Chemistry; $3^{\text {rd }}$ Ed.; McGraw-Hill: New York, 1966; p 17.

[12] Hepler, L. G. Chemical Principles; Blaisdell: New York, 1964; p 5-6.

[13] Fahrenheit had originally chosen the freezing point of seawater as the lower reference point for his temperature scale and assigned that a numerical value of $0^{\circ} \mathrm{F}$, but since the composition of seawater can vary significantly, not long thereafter he changed the lower reference point to the freezing point of pure water and assigned that the numerical value we know and use today.

[14] If you don't already know the temperature that has the same numerical value on both scales, it's easily found by substituting $x$ for both $T_{\mathrm{C}}$ and $T_{\mathrm{F}}$ in Equation (1) and solving for $x$.

[15] Perhaps it would be palliative to recall that $-40^{\circ} \mathrm{C} / \mathrm{F}$ is very close to the freezing point of the elemental mercury that is sometimes used to make thermometers. I know I feel better now.

[16] I have not provided a link for that online source here, because (a) shocking as it may sound, internet links have been known to change or disappear altogether; (b) whoever posted the formulae stated that they had no idea why the formulae worked, from which I divined that the formulae had not been posted by the person who had derived them; and (c) given the first two reasons, I neglected to note the URL at the time, and I have been unable to find it again. (To be fair, I had just suffered a huge emotional let-down, and I had not yet anticipated writing this manuscript.) For some weeks I tried to track down the originator of Equations (11) and (12) using all of the hardcopy and online resources at my disposal, including SciFinder ${ }^{\circledR}$, all to no avail. Almost as an afterthought, on an impulse I picked up an old textbook, one I recall fondly, and lo and behold, among the exercises that followed the chapter containing the usual temperature conversion formulae, there they were, in glorious black and white. Even though there was no reference to another source for them, it should not be assumed that the author of that textbook was the first to derive them, but knowing what I do of him (including two Nobel prizes), I'd like to believe so. I had the privilege to hear him speak, and he was a true gentleman, kind, and a professors' professor. Readers may likewise view them reverently by 
International Journal of Education (IJE) Vol.9, No.2, June 2021

consulting: Linus Pauling, College Chemistry; $3^{\text {rd }}$ Ed.; W. H. Freeman: San Francisco, 1964; p 17-18, exercises 1-10 and 1-11.

[17] Apologies to Bob Dylan.

[18] Perhaps like me, some of you are asking, "Why aren't Equations (11) and (12) included in more, if not all textbooks that discus temperature conversions?" That, I cannot answer, but I think it's a good question; one worth asking. Surely, presenting more than one set of equations for calculating the conversions would be a perfect opportunity to provoke student questions, stimulate discussion, and illustrate the value of reflection. 
International Journal of Education (IJE) Vol.9, No.2, June 2021 